\title{
Premenstrual Symptoms And Academic Performance Among Adolescent Girls
}

\author{
P. Padmavathi* ${ }^{1}$, S. Raja Sankar ${ }^{2}$, N. Kokilavani ${ }^{3}$ \\ ${ }^{1}$ Principal,Dhanvantri College of Nursing,,Ganapathypuram, Namakkal District \\ ${ }^{2}$ Associate professor, Melmaruvathur Adhiparasakthi Institute of Medical Sciences (MAPIMS) \\ ${ }^{3}$ Principal, Adhiparasakthi Collège Of Nursing, Melmaruvathur
}

\section{Abstract}

Premenstrual syndrome is a psychophysiological stress induced disorder. Stress disturbs the balance of sympathetic and parasympathetic nervous system. Changes in heart rate and blood pressure are the most important physiological response following stress. To correlate the premenstrual symptoms and academic performance among adolescent girls. A correlational survey was adopted for the study Setting: Higher secondary school, Namakkal District. 60 adolescent girls fulfilling the inclusion criteria were selected by simple random sampling technique. All participants were given a questionnaire to complete; questions were related to Baseline Proforma of adolescent girls, rating scale on the common premenstrual symptoms, Student life stress Inventory, Academic Demand Distress were given 40 minutes to complete the questionnaire. The findings revealed that, there was significantly higher numbers of symptoms perceived $8.46 \pm 2.9$ follicular and $7.14 \pm 2.8$, luteal, $\mathrm{p}=.001$ and higher distress (1.25 \pm 0.41 follicular and $1.52 \pm 0.31$ luteal, $\mathrm{p}=.003$ ) in the follicular phase than in the luteal phase. The academic demand component of academic stress measured daily frequency and distress associated with assignments, papers, projects/presentation and time studying. Within the follicular phase number of assignments due was significantly correlated to symptom perception and distress $(.41, .31$, respectively) and the number of projects/presentations due was correlated to symptom distress (.29) at $\mathrm{p}<.05$. There were significant correlations between follicular phase symptom perception and distress, and luteal phase symptom distress with academic demand distress. There was significant correlation between premenstrual symptoms and academic performance.

Key Words: Academic performance, Academic Distress, adolescents, Premenstrual syndrome

\section{INTRODUCTION}

$\mathrm{M}$ enstruation is typically a universal event during a woman's reproductive life, and up to $90 \%$ report perceiving one or more symptoms during the days before menstruation. More than 200 premenstrual symptoms have been identified over the last 50 years, which encompass three main factors: negative mood, pain and discomfort, and bloating. Nearly all components of normal functioning for women can be affected by the changes related to phase of the menstrual cycle in either a negative or a positive way. Prevalence ranges from reports that suggest $5-20 \%$ have moderate to severe clinically relevant premenstrual complaints and up to $75 \%$ of all women of fertile age may experience symptoms of premenstrual syndrome. Premenstrual symptoms associated with premenstrual syndrome (PMS) may impair the overall physical health of a woman as well as interpersonal relationships, daily routine, and work productivity[1].

Premenstrual Syndrome (PMS) is a set of physical, emotional and behavioural symptom that start during the week preceding menstruation and are alleviated when the menstrual flow begins. The symptoms present a cyclic and recurrent character with variable in quality and intensity.

Symptoms experienced by women premenstrually vary, but most experience some symptoms that signal menstruation is approaching. Stress, particularly chronic stress, is known to negatively affect both prevalence and severity of premenstrual symptoms. A functional definition of stress is the number of stressors endorsed. Chronic stressors have been implicated in the development of certain somatic illnesses and for women the dimension of chronicity has been shown to account for a

\section{Address for correspondence*}

Ms. P. PADMAVATHI, M.Sc (Nursing), Ph. D(N)

Principal,Dhanvantri College of Nursing,,Ganapathypuram, Namakkal DistrictNO - 1 Ranganoor Road,

Muniyappan kovil, Pallakkapalyam,Namakkal District - 637 303 significant amount of variation in psychological and physical well-being. However, the role of academic stress as a possible chronic stressor for students is not well understood. Academic stress involves multiple stressors particular to students such as academic, financial, time, health related and self-imposed types of stressor[2].

The most common physical symptomsare headaches, breast tenderness, swelling, abdominalbloating, heaviness, low energy, tired and weak, back and muscle pain, sleep more, stay in bed increased / decreased appetite, and crave food), and emotional symptoms are (depressed mood, sad, lonely, anxious, nervous, mood swings, trouble with relationships, irritable, angry, impatient,difficulty concentrating, feel out of control, cannot cope, less productive in job or home and avoid social activity. These symptoms sufficient to impair daily activities, A woman's experience of premenstrual symptoms has been found to reduce work efficiency, increase absenteeism, and negatively impact on family[3].

Premenstrual symptoms have been associated with perceived stress, whereby perceived stress was the strongest predictor of Premenstrual Syndrome and had a significant positive correlation to all premenstrual symptom groups. Perceived stress in the college/university setting may take the form of academic stress. Negative health outcomes, including depression and physical illness have been associated with academic stress. In addition women may display greater behavioral and physiological reactions to academic stressors [4].

Academic stress, viewed as a chronic stress due to the nature of academic demands; was associated with negative health outcomes of depression and physical illness. It is therefore conceived that academic stress experienced by female college students may be implicated as negatively affecting the premenstrual symptom experience.

PMS is related to high suicide and accident rates, employment and school absentee rates, poor academic performance and acute psychiatric problems. PM symptoms are 
more common and more sever among high-level educated women than non - educated women with a possible association of stress with PMS, (Addis Tenkir, Nebreed Fisseha, Biniyam Ayele, 2002).

Determine the prevalence of PMS and its effect on theacademic and social performances of studentsof Jimma University (JU). The study reported that, the age of participants ranged from 17 to 38 years, with mean \& median age of $20.3 \&$ 20years, respectively. Almost all (99.6\%) had at least one premenstrual (PM) symptom in many of themenstrual cycles in the last 12 months. The prevalence of PMS or premenstrual dysphoric disorder(according to DSM-IV) was $27 \%$. About $14 \%$ of the study participants frequently missed classesand $15 \%$ missed examinations or scored a lower grade at least once because of PM symptoms. Bothwere significantly associated with severity of symptoms $(\mathrm{p}<0.005)$. More first year students wereaffected by PMS than students of other class-years $(\mathrm{p}<0.05)$.It concluded thata high prevalence and negative impact of PMS on students ofJimma University. Therefore, health education, appropriate medical treatment and counselingservices, as part and parcel of the overall health service, should be availed and provided to affectedwomen, (Addis Tenkir, Nebreed Fisseha, Biniyam Ayele, 2002).

Menstrual cycle moods and symptoms may well play a discernible role in the academic performance of some postpubescent adolescent female students. The study reported that, at the premenstrual, menstrual, and intermenstrual phases, moods and symptoms significantly predicted grades in 14 per cent, 7 per cent, and 13 per cent of instances, respectively. Although most significant relationships were negative, scores on the MDQ Arousal scale for the intermenstrual phase positively predicted grades in English Literature, (general) Mathematics, Art and Craft, History, Mathematics 1, and Study of Society. Evidently, menstrual cycle variables play a small, but discernible role on academic learning outcomes, contributing both positively and negatively to performance. Future, prospective studies are now needed to provide a more definitive account of menstrual cycle influences on academic performance.

Many adolescent girls experience various premenstrual physical, emotional or behavioral changes, which at times reach such levels of severity that may have substantial social impact upon theherself, her associates, her work and academic performance. So correlations study to assess the premenstrual symptoms and academic performance among adolescent girls.

\section{Statement Of The Problem}

A correlation study on premenstrual symptoms and academic performance among adolescent girls in selected school, Namakkal (Dt).

Objectives

1.To correlate the premenstrual symptoms and academic performance among adolescent girls

2.To find out the association between premenstrual symptoms and their demographic variables among adolescent girls.

3.To find out the association between academic performance and their demographic variables among adolescent girls.

Assumption
The study assume that,

$\S$ Premenstrual symptoms are common among adolescent girls.

$\S$ Premenstrual syndrome is a major cause of less academic performance and school absenteeism among students who suffer from the same.

Delimitations

The study is limited to, District.

1.A study setting selected was school in Namakkal

2.Adolescent girls who were present at the time of data collection.

3.Adolescent girls who were willingly participated in the study.

\section{MATERIALS AND METHODS}

\section{Research approach}

Research that explores the interrelationships among variables of interest without intervention on the part of the researcher is a correlation study. In the present study, the investigator intended to correlate the premenstrual symptoms and academic performance

\section{Research design}

The research design selected for the present study was correlational descriptive design. The present study attempts to correlate the premenstrual symptoms and academic performanceamong adolescent girls. Therefore a correlational survey was found to be an appropriate research design .

\section{Variables}

Dependent variable $\quad-\quad$ premenstrual symptoms and academic performance

Associate variable - $\quad$ Selected background factors

\section{Research setting}

The study was conducted in Higher Secondary school, Namakkal District.

\section{Population}

The population for the present study was all the adolescent girls between the age group of $14-18$ years in selected school, Namakkal District.

\section{Sample}

The sample consisted of 60 adolescent girls of Higher secondary school, Namakkal District.

\section{Sampling technique:}

Simple random sampling technique was used to select the sample for the study.

\section{Development of tool}

A baseline Proforma, rating scale on common premenstrual symptoms, Students life Stress Inventory (SSI) and academic demand was prepared with the help of review of literature, personal experience and discussion with experts.

Description of the tool 
Section A: Baseline Proforma of the samples

Section B: Rating scale on common premenstrual symptoms (Scores range $45-180$ )

Section C : Students life Stress Inventory (SSI) (Scores range 51 -255)

Section D: Academic stress and Academic demand - It consisted of number of assignments due, number of papers due, number of projects/presentations due daily on a scale of $0-10(0=$ no distress and 10-extreme or the most distress). A daily distress score (range0 to 30). To account for time spent studying, each day participants recorded hours and minutes spent as well the distress caused by studying on a scale of $0-10(0=$ no distress and $10-$ extreme or the most distress).

\section{Tools are prepared in English and translated in Tamil}

Section A: Baseline Proforma

It contained items for obtaining information regarding age, age at menarche, duration of cycle, type of flow, family history of PMS, school absenteeism, source of information and use of home remedies

Section B: Rating scale on common premenstrual symptoms

It consisted of 45 items in different areas. The subjects had to tick mark in the relevant column based on the No symptoms, Mild, Moderate and Extreme symptoms. The maximum score was 180 and the minimum score was 45 . The more severe the symptoms are higher the score.

Section C : Academic stress - Students life Stress Inventory (SSI). This inventory contains statement dealing with to assess the students' perceived academic stress and reactions to stress. There are 51 items arranged on a Likert response format $(1=$ never true to $5=$ always true) that assessed five categories of academic stressors (frustrations, conflicts, pressures, changes, and selfimposed), and four categories describing reactions to stressors (physiological, emotional, behavioral, and cognitive). Read it carefully and respond to each statement as it has related or is relating to you as a student. A higher score was indicative of greater stress and reactions to stress.

\section{$\mathbf{0}=$ Never \\ $1=$ Seldom \\ $2=$ Occasionally \\ $3=$ Often \\ $4=$ Most of the time}

Scoring: Students life Stress Inventory (SSI) consisted of 51 items, out of which 23 Stressor items (frustrations, conflicts, pressures changes and self-imposed) with a range from $23-115$ and 28 items in the Reactions to Stressors category (physiological, emotional, behavioral and cognitive appraisal) with a range from 28-140. The Total Stress score from both categories range from 51-255.

Section D: Academic stress and Academic demand - It consisted of number of assignments due, number of papers due, number of projects/presentations due daily on a scale of $0-10(0=$ no distress and 10-extreme or the most distress). A daily distress score (range0 to 30). To account for time spent studying, each day participants recorded hours and minutes spent as well the distress caused by studying on a scale of $0-10(0=$ no distress and $10-$ extreme or the most distress).

\section{Data collection procedure}

The data on The Students life Stress Inventory (SSI), Common premenstrual symptoms and Academic stress and Academic demand were collected from Higher secondary school adolescent girls. The data were collected for 8 weeks in the month of June to July 2013. Permission was sought and obtaining from school headmaster. The adolescent girls were selected using simple random sampling method among those who fulfilled the sample selection. Informed consent was obtained from the adolescent girls. The questionnaires were administered to the adolescent girls regarding The Students life Stress Inventory (SSI), common premenstrual symptoms and Academic stress and Academic demand. Confidentiality of the information shared was assured. The adolescent girls were co operative. On an average, it took 40 minutes to complete one sample.

\section{Plan for data analysis}

The data were analysed by using both descriptive and inferential statistics

ØBaseline proforma of the samples were described by frequency and percentage distribution

ØCorrelation of premenstrual symptoms and academic performance among adolescent girls were analyzed by using mean, standard deviation and ' $r$ ' value

ØThe association between premenstrual symptoms and their demographic variables among adolescent girls were analyzed by using linear regression

ØThe association between academic performance and their demographic variables among adolescent girls were analyzed by using linear regression

\section{RESULTS}

Section A: Most (62\%) of the adolescents girls were in the age group of $15-16$ years. However $82 \%$ of the adolescents girls attained menarche at the age of above 13years, $75 \%$ of adolescents girls were in $>28$ days cycle, Most $(72 \%)$ of adolescents girls were 5-7 days flow, $67 \%$ of them had family history of premenstrual syndrome, $53 \%$ of adolescents girls had low academic performance $49 \%$ of adolescents girls were school absenteeism, $52 \%$ of them had source of information from peers and $63 \%$ of the taking self treatment.

Section B: The findings revealed that the correlation between premenstrual symptoms and academic performance among adolescent girls.

\section{Symptom Perception, Severity and Distress}

\section{Mean, SD and Correlations Between Overall Perceived Stress to Stressors, Reactions to Stressors and Total Stress Score}

\begin{tabular}{|l|l|l|l|l|}
\hline $\begin{array}{l}\text { Adolescen t } \\
\text { girls }\end{array}$ & $\begin{array}{l}\text { Max. } \\
\text { Scores }\end{array}$ & M ean & SD & $\begin{array}{l}\text { 'r' } \\
\text { value }\end{array}$ \\
\hline Stressors & 115 & 53.5 & 4.61 & 0.56 \\
\hline $\begin{array}{l}\text { Reactions to } \\
\text { stressors }\end{array}$ & 140 & 78.6 & 6.75 & 0.35 \\
\hline $\begin{array}{l}\text { Total stress } \\
\text { score }\end{array}$ & 255 & 121.43 & 7.12 & 0.47 \\
\hline
\end{tabular}


Academic Demands by Follicular Phase, Luteal Phase and Distress Level

\begin{tabular}{|l|l|l|l|l|l|l|l|l|}
\hline \multirow{2}{*}{ A cade mic Demands } & \multicolumn{2}{l|}{$\begin{array}{l}\text { Follicu lar } \\
\text { Phase }\end{array}$} & \multicolumn{3}{l|}{ Distress Level } & \multicolumn{2}{l|}{ Lut eal Ph ase } & \multicolumn{2}{l|}{$\begin{array}{l}\text { D istress } \\
\text { Level }\end{array}$} \\
\cline { 2 - 10 } & M ean & SD & M ean & SD & M ean & SD & M ean & SD \\
\hline A ssignments & 1.43 & 0.43 & 1.24 & 0.72 & 0.98 & 0.58 & 1.24 & 0.62 \\
\hline Papers & 0.38 & 0.78 & 0.83 & 1.92 & 1.21 & 0.24 & 0.92 & 1.24 \\
\hline Projects/presentations & 0.47 & 0.64 & 1.19 & 1.14 & 1.31 & 0.34 & 0.84 & 1.26 \\
\hline T ime studying & 122.3 & 98.42 & 1.43 & 1.72 & 109.33 & 79.62 & 1.74 & 1.14 \\
\hline
\end{tabular}

Correlations Between Follicular Phase and Luteal Phase

Symptom Perception, Severity and Distress with Academic

\begin{tabular}{|l|l|l|l|l|}
\hline $\begin{array}{l}\text { Phase } \\
\text { (Minutes) }\end{array}$ & $\begin{array}{l}\text { Assignm } \\
\text { ent }\end{array}$ & $\begin{array}{l}\text { Paper } \\
\text { s }\end{array}$ & $\begin{array}{l}\text { Projects/Present } \\
\text { ations }\end{array}$ & $\begin{array}{l}\text { Time } \\
\text { Studying }\end{array}$ \\
\hline Follicular Phase \\
\hline Perception & $0.41^{*}$ & 0.21 & 0.07 & 0.05 \\
\hline Severity & 0.06 & -0.19 & -0.19 & 0.16 \\
\hline Distress & $0.31^{* *}$ & 0.12 & $0.29^{*}$ & 0.18 \\
\hline Luteal Phase \\
\hline Perception & 0.07 & 0.03 & -0.11 & 0.01 \\
\hline Severity & -0.02 & -0.01 & -0.08 & 0.12 \\
\hline Distress & 0.29 & 0.05 & 0.01 & 0.14 \\
\hline
\end{tabular}

Correlations Between Follicular Phase and Luteal Phase Symptom Perception, Severity and Distress with Academic Demand

\begin{tabular}{|l|c|l|l|l|}
\hline Phase (Minu tes) & $\begin{array}{l}\text { Assignmen } \\
\mathbf{t}\end{array}$ & Papers & $\begin{array}{l}\text { Project s/Presen tation } \\
\mathbf{s}\end{array}$ & $\begin{array}{l}\text { Time } \\
\text { Stud ying }\end{array}$ \\
\hline Follicular Phase \\
\hline Perc eption & $0.41^{*}$ & 0.21 & 0.07 & 0.05 \\
\hline Severity & 0.06 & -0.19 & -0.19 & 0.16 \\
\hline Distress & $0.31^{* *}$ & 0.12 & $0.29^{*}$ & 0.18 \\
\hline Luteal Phase \\
\hline Perc eption & 0.07 & 0.03 & -0.11 & 0.01 \\
\hline Severity & -0.02 & -0.01 & -0.08 & 0.12 \\
\hline Distress & 0.29 & 0.05 & 0.01 & 0.14 \\
\hline
\end{tabular}

Correlations Between Follicular Phase and Luteal Phase Symptom Perception, Severity and Distress with Academic Demand Distress

\begin{tabular}{|l|c|c|c|c|}
\hline Ph ase (Minu tes) & $\begin{array}{l}\text { A ssignme } \\
\text { nt }\end{array}$ & Papers & $\begin{array}{l}\text { Projects/Present ati } \\
\text { ons }\end{array}$ & $\begin{array}{l}\text { Time } \\
\text { St ud ying }\end{array}$ \\
\hline Follicular Phase \\
\hline Perc eption & $0.39^{* *}$ & $0.28^{*}$ & $0.25^{*}$ & $0.22^{*}$ \\
\hline Severity & 0.06 & -0.07 & -0.12 & 0.11 \\
\hline Distress & $0.63^{* *}$ & $0.52^{* *}$ & $0.54^{*}$ & $0.39^{* *}$ \\
\hline Luteal Phase & \multicolumn{5}{|l|}{} \\
\hline Perc eption & 0.27 & 0.16 & -0.07 & 0.21 \\
\hline Severity & -0.04 & -0.07 & -0.02 & 0.08 \\
\hline Distress & $0.46^{* *}$ & $0.42^{* *}$ & $0.34^{*}$ & $0.54^{* *}$ \\
\hline
\end{tabular}

The sample the mean follicular phase was $12.24 \pm 3.7$ days, with $8.46 \pm 2.9$ symptoms perceived, with $2.24 \pm 0.12$ severity, and $1.25 \pm 0.41$ distress. The luteal phase for all participants was calculated as 14 days. The mean number of symptoms perceived in this phase was $7.14 \pm 2.8$, with $2.89 \pm 0.52$ severity, and $1.52 \pm 0.31$ distress. A significant difference in symptom perception ( $\mathrm{p}=.001$ ) occurred with a higher number of symptoms perceived in the follicular phase. In addition there was a significant difference in symptom distress $(\mathrm{p}=.003)$ where higher symptom distress occurred in the follicular phase.

2.Mean, SD and Correlations Between Overall Perceived Stress to Stressors, Reactions to Stressors and Total Stress Score
Significant correlations were noted between the Overall Perceived Stress and the Stressors category as well as the Total Stress Score. Not surprisingly there was no significant correlation between Overall Perceived Stress rating and the Reactions to Stressors.

3. Academic Demands by Follicular Phase, Luteal Phase and Distress Level

4.Correlations Between Follicular Phase and Luteal Phase Symptom Perception, Severity and Distress with Academic Demand

In follicular phase, number of assignments due was significantly correlated to symptom perception and distress $(0.41$ and 0.31 respectively) and the number of projects/presentations due was correlated to symptoms distress $(0.29)$. There were no statistically significant correlations between academic demand and luteal phase symptom perception, severity, or distress.

5.Correlations Between Follicular Phase and Luteal Phase Symptom Perception, Severity and Distress with Academic Demand Distress

Section C: The findings shows that there is no significant relationship between premenstrual symptoms and background factors of adolescent girls such as age at menarche, duration of cycle, type of flow, family history of PMS , school absenteeism and use of home remedies.

Section D: The findings shows that there is no significant relationship between academic performance and background factors of adolescent girls such as age at menarche, type of flow, family history of PMS and use of home remedies. But significant relationship between premenstrual symptoms and background factors of adolescent girls such as duration of cycle, age and school absenteeism.

\section{DISCUSSION}

éThere was significant correlation between premenstrual symptoms and academic performance. Within the follicular phase number of assignments due was significantly correlated to symptom perception and distress $(.31, .37$, respectively) and the number of projects/presentations due was correlated to symptom distress (.25) at $\mathrm{p}<.05$. There were significant correlations between follicular phase symptom perception and distress, and luteal phase symptom distress with academic demand distress for assignments, papers, projects/presentations and time studying, indicating a relationship between distress components of symptom experience and some components of academic stress. (Pamela Lou Hulstein, 2009)

éThere was no significant association $(\mathrm{P}>0.05)$ between the premenstrual symptoms and selected demographic variables.

éThere was no significant association $(\mathrm{P}>0.05)$ between the academic performance and selected demographic variables.

\section{RECOMMENDATIONS}

From this study, we can conclude that the oral administration of nutmeg extract have beneficial effects on blood glucose levels. 1. A study can be conducted with large samples to generalize the findings.

2.A comparative study can be done between urban and 
rural adolescent girls.

3.A comparative study can be done between educated and 